\title{
Colonic Strictures after Necrotizing Enterocolitis in Infants: Case Series
}

\author{
Shakya VC ${ }^{1}$, Agrawal CS $^{2}$, Shrestha $\mathrm{AB}^{3}$, Pradhan $\mathrm{A}^{4}$, Poudel $\mathrm{P}^{5}$, Sah $\mathrm{P}^{6}$, Adhikary $\mathrm{S}^{7}$
}

${ }^{1}$ Dr. Vikal Chandra Shakya, MBBS, MS, ${ }^{2}$ Prof. Chandra Shekhar Agrawal, MBBS, MS, ${ }^{3}$ Dr. Amit Bahadur Shrestha, MBBS, MS. Department of Surgery, ${ }^{4}$ Dr. Anju Pradhan, MBBS, MD. Department of Pathology, ${ }^{5}$ Dr Prakash Poudel, MBBS, MD. Department of Paediatrics, ${ }^{6}$ Dr. Pannalal Sah, MBBS, MD. Department of Radiology, ${ }^{7}$ Prof. Shailesh Adhikary, MBBS, MS, Department of Surgery, All from B. P. Koirala Institute of Health Sciences, Dharan, Nepal.

Address of correspondence: Dr. Vikal Chandra Shakya, E-mail: vikalcsh@yahoo.com

\begin{abstract}
The fate of neonates with necrotizing enterocolitis is variable, with colonic strictures being one rare phenomenon after the insult. We describe here two infants with colonic strictures, which developed secondary to neonatal necrotizing enterocolitis. Infants recovered or in the process of recovery after it should be investigated for possibility of development of colonic strictures.
\end{abstract}

Keywords: Colonic strictures, necrotizing enterocolitis, barium enema, stoma

\section{Introduction}

$\mathrm{N}$ ecrotizing enterocolitis (NEC) is the leading cause of morbidity in neonates and is the most common gastrointestinal emergency seen in most neonatal intensive care units ${ }^{1}$. Improvements in neonatal care have led to increased survival rates. This decrease in mortality has resulted in an increase in long-term complications such as intestinal strictures ${ }^{1}$. The incidence of post-NEC strictures has been reported as $14 \%$ to $36 \%{ }^{1}$. Studies from South Asia are relatively lacking regarding this entity ${ }^{2}$. We describe here two cases of colonic stricture who have presented in the post-neonatal period due to colonic strictures which was secondary to neonatal necrotizing enterocolitis.

\section{Case reports}

Case one: A 2.5 months old female child presented with history of gradual abdominal distension, not passing stool and flatus and persistent bilious vomiting for 3 days. She had a previous history of being admitted at 3rd day of life with similar illness, which subsided on conservative management. Her haemodynamics was stable. Abdominal examination showed the abdomen to be distended with visible bowel loops. Abdominal radiographs suggested dilated bowel loops (Fig. 1). After resuscitation, an emergency laparotomy was performed, keeping a provisional diagnosis of Hirschsprung's disease. The operative findings was that of dilated small bowel loops, caecum and ascending colon with a narrowing at the right part of the transverse colon, and distal collapsed bowel (Fig. 2A). Careful dissection of the narrowing and its resection showed it to be two adjacent strictures; after resection, colo-colic anastomosis was done. The child was kept nil per oral for 4 days, she improved postoperatively, without major complications. Biopsy suggested inflammatory strictures (Fig. 3A).

Case two: A three months old male child presented with the complaints of distension of abdomen, not passing stool and flatus for 5 days. On examination, the child was dehydrated and lethargic, abdominal examination showed distended abdomen with palpable bowel loops, rectal examination showed an empty collapsed rectum. An X-ray of the abdomen showed multiple dilated bowel loops with absent air in the rectum (Fig 4A); exploratory laparotomy showed a stricture at the descending colon (Fig. 4B). Resection of the stricture bowel along with a double-barrel colostomy was done and rectal biopsy was taken to look for ganglion cells to rule out associated Hirschsprung's disease. Biopsy suggested inflammatory stricture and ganglion cells were present in the rectal biopsy. After 3 months, colostomy closure was done. The post operative recovery was uneventful. 


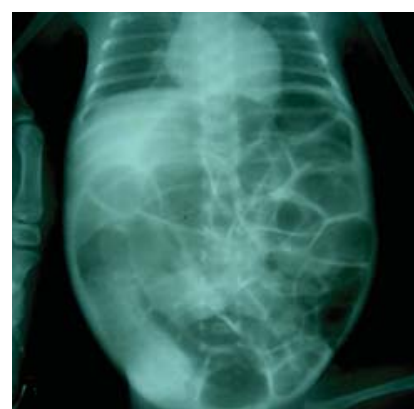

Fig 1: Plain X-Ray of the abdomen showing dilated bowel loops
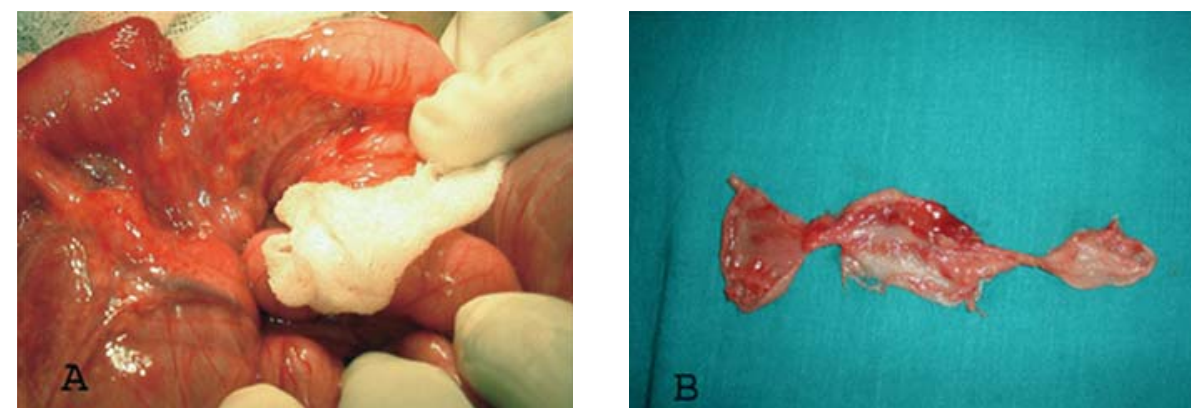

Fig 2: A. Laparotomy showing strictured segment with adhesions at transverse colon B. On dissection, stricture was found at two adjacent sites
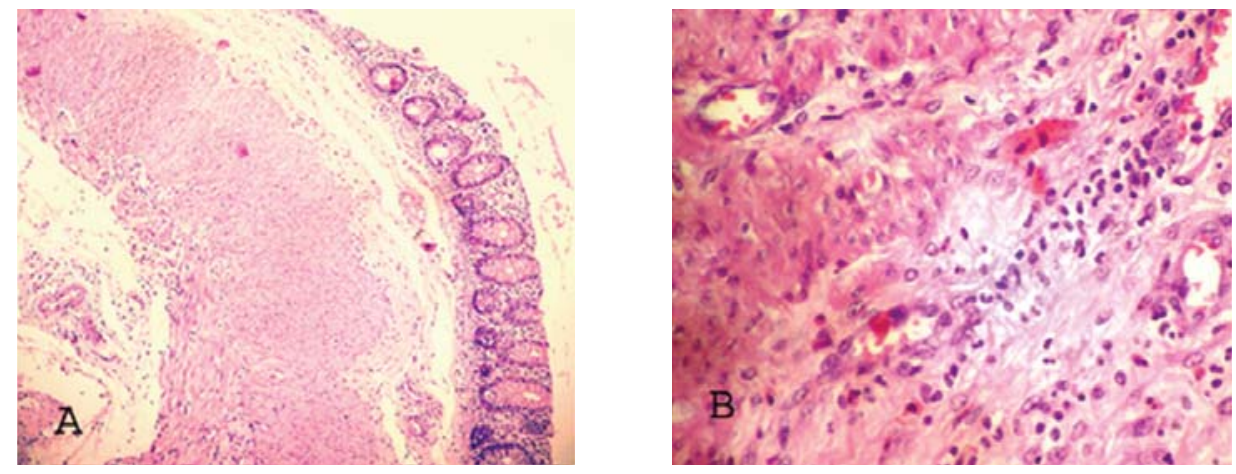

Fig 3: A. Photomicrograph showing mucosal inflammation, submucosal edema and congestion, thickened hypertrophic muscle layer; serosa shows edema, congestion and fibrosis (H\&E stain, 4X). B. The submucosal layer shows mixed inflammatory cells infiltration, predominantly neutrophils, then lymphocytes, eosinophils and histiocytes, edema and fibrosis; muscle layer shows mild inflammation (H\&E stain, 20X)
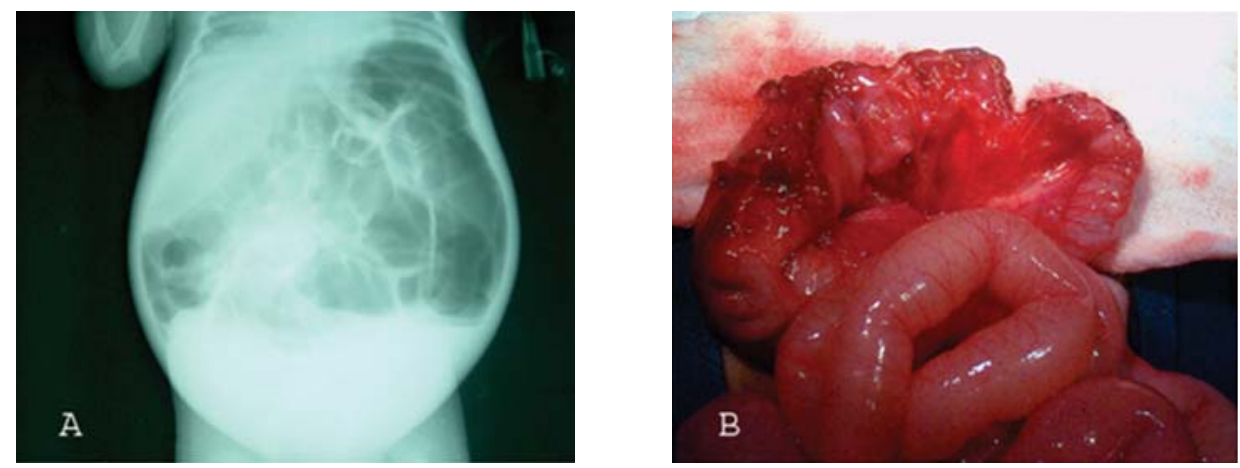

Fig 4: A. Plain radiograph shows dilated bowel loops with absent air at the rectum B. Laparotomy showing stricture at the descending colon.

\section{Discussion}

Rabinowitz in 1968 first described a stricture in the descending colon of an infant who had an episode of NEC one month $\operatorname{ago}^{3}$. The survival among infants with NEC has improved significantly in the past decade; some survivors can develop intestinal obstruction subsequently. Intestinal stricture forms due to reparative process following an acute decrease in flow through the intramural blood vessels (ischemic injury) ${ }^{4}$. Ischemic injury of the colon may result in transmural gangrene, bleeding and ulceration and then subsequent healing of the mucosa ${ }^{5}$. The extent of intraluminal colonic narrowing depends not only on the severity of the ischemic episode but also on the length of time after the acute event. Early strictures demonstrate mucosal hypertrophy, edema, and granulation tissue formation. With time, progressive fibrosis can result in complete luminal blockage due to stricture formation ${ }^{6}$.

The most common symptom in medically managed NEC patients is abdominal distension, then vomiting, 
haematochezia, or episodes of apnea and bradycardia ${ }^{1}$. Infants who develop stricture usually have a poor weight gain some amount of abdominal distention, and persistent vomiting. Often, these symptoms are confused with recurrent NEC. No specific criteria have been yet identified to predict which patients could be at risk for post-NEC strictures. An intestinal stricture is usually most common at the colon, and can develop within 3 weeks to 3 months after both medical and surgical treatment for NEC and in both the functional and defunctionalized bowel ${ }^{6}$. In our second case, there was no history suggestive of NEC. Probably, he suffered from a subclinical disease. Like in the present case, subclinical NEC has also been found to result in stricture as in Singh et al's report ${ }^{2}$. Occasional cases of spontaneous resolution of colonic strictures has also been reported?

In recent years, there has been a significant increase in the percentage of patients with NEC receiving surgical intervention ${ }^{1}$. The surgical indications for NEC have changed in the west over the last 10 years. An increasing number of NEC patients are receiving surgical treatment for their post-NEC stricture rather than for acute NEC. The operation for stricture consists of resection of the abnormal segment, with generous margins. If the infant is acutely ill from intestinal obstruction, primary anastomosis should be avoided and the bowel ends should be exteriorized. Alternatively, in such infants, a diverting colostomy or enterostomy may be performed, with resection of the stricture at a later operation. In all surgically-treated survivors of NEC, it is mandatory to obtain a barium enema prior to stoma closure, to rule out distal stricture. Usually this is carried out 6 to 12 weeks after the acute episode of NEC, when the infant is in a good nutritional state.

In medically treated patients, authors have found a significant incidence of colonic stricture after NEC; hence it is believed that a barium enema is indicated in all medically-treated survivors of NEC. It has even been proposed that the radiological evaluation should be done even prior to the onset of obstructive symptoms so that the risk of death or complications may be decreased, preferably at about 3 weeks ${ }^{6}$. Balloon catheters have also been used for dilatation of ischemic intestinal strictures, and this has obviated the need for surgical resection of the stricture or resulted in a more limited surgical procedure ${ }^{4}$. Recent studies have also demonstrated laparoscopic success in the management of intestinal strictures in the infantile period using either an intra- or extracorporeal resection and anastomosis ${ }^{8}$.

\section{References}

1. Bütter $A$, Flageole $H$, Laberge JM. The changing face of surgical indications for necrotizing enterocolitis. J Pediatr Surg 2002;37(3):496-9.

2. Singh S, Bhosle VG, Singh D, Karmarkar SJ. Post inflammatory colonic strictures in early childhood and their management. Bombay Hospital Journal 2002;44(2):287-9.

3. Rabinowitz JG, Wolf BS, Feller MR. Krasna I. Colonic changes following necrotizing enterocolitis in the newborn. AJR 1968;103:359-64.

4. Ball WS Jr, Seigel RS, Goldthorn JF, Kosloske AM. Colonic strictures in infants following intestinal ischemia. Treatment by balloon catheter dilatation. Radiology 1983;149(2):469-71.

5. Marston A, Pheils MT, Thomas ML, Morson BC. Ischemic colitis. Gut 1966;7:1-15.

6. Kosloske AM, Burstein J, Bartow SA. Intestinal obstruction due to colonic stricture following neonatal necrotizing enterocolitis. Ann Surg 1980;192:202-7.

7. Tonkin ILD, Bjelland JC, Hunter TB, Capp MP, Firor $H$, Ermocilla R. Spontaneous resolution of colonic strictures caused by necrotizing enterocolitis: therapeutic implications. AJR 1978;130:1077-81.

8. Martinez-Ferro $M$, Rothenberg $S$, St Peter $S$, Bignon H, Holcomb G. Laparoscopic treatment of postnecrotizing enterocolitis colonic strictures. J Laparoendosc Adv Surg Tech A 2010;20(5):477-80.

\section{How to cite this article?}

Shakya VC, Agrawal CS, Shrestha AB, Pradhan A, Poudel P, Sah P, Adhikary S. Colonic Strictures after Necrotizing Enterocolitis in Infants - Case Series. J Nep Paedtr Soc 2011;31(2):127-129. 